\title{
Cloning, Nucleotide Sequencing, and Expression in Escherichia coli of a Lipase and Its Activator Genes from Pseudomonas sp. KWI-56
}

\author{
Taro Iizumi, Koichi Nakamura, Yuji Shimada,* Akio Sugihara,* \\ Yoshio Tominaga* and Tetsuro FuKaSE \\ Kurita Central Laboratories, Kurita Water Industries Ltd., \\ 7-1 Wakamiya, Morinosato, Atsugi 243-01, Japan \\ * Osaka Municipal Technical Research Institute, \\ Morinomiya, Joto-ku, Osaka 536, Japan
}

Received March 19, 1991

\begin{abstract}
A lipase gene (lip) and its activator gene (act) on a $2.9 \mathrm{~kb} B g / \mathrm{II}-E c o$ RI fragment from Pseudomonas sp. KWI-56 were cloned in Escherichia coli using pUC19 as a vector plasmid. From the sequencing results, the open reading frames of the lip and the act were found to contain 1092 and 1032 nucleotides, respectively. The act existed downstream of the lip with the same orientation. When the lip was expressed in $E$. coli using the lac promoter on the $\mathrm{pUC}$ plasmid vector, the lipase activity of $E$. coli carrying both the lip and the act was 200 -fold greater than that carrying only the lip. This result suggested the act was important in the expression of the lip in $E$. coli.
\end{abstract}

Lipase catalyzes the hydrolysis of triacylglycerol and is a well-known extracellular, inducible enzyme of the genus Pseudomonas. Recently, some structual genes of lipase from genus Pseudomonas have been cloned. ${ }^{1-4)}$ The nucleotides of the lipase genes from $P$. fragi were sequenced, and they were expressed in Escherichia coli. ${ }^{3,4)}$ However, few reports have appeared concerned with genetic studies on regulation, secretion, and expression of lipase activity.

During the course of cloning of the lipase gene (lip) from $P$. sp. KWI-56, an extracellular thermostable lipase producer, ${ }^{5}$ we have found that the lipase activity was enhanced in $E$. coli by the function of the activator gene (act) existing downstream of the lip. ${ }^{6}$ This paper describes the cloning and sequencing of the lip and the act from $P$. sp. KWI-56.

\section{Materials and Methods}

Bacterial strain and plasmids. E. coli $\mathrm{HB} 101$ and E. coli JM103 were used as host for the recombinant plasmids. Pseudomonas sp. KWI-56 (KWI-56) ${ }^{\text {5) }}$ was used as a DNA donor. The vectors used for the cloning experiments were M13mp18, M13mp19, pUC18, pUC19, ${ }^{7}$ and pHSG299. ${ }^{8 !}$
Media and cultivation. Nutrient broth and LB were used for the cultivation of KWI-56 and E. coli, respectively. Tributyrin-LB agar ${ }^{3}$ was used to detect the lipase activity of transformants. When the transformants were cultivated, ampicillin (Ap) and kanamycin $(\mathrm{Km})$ were added at a final concentration of $50 \mu \mathrm{g} / \mathrm{ml}$ each.

Recombinant DNA techniques. Chromosomal DNA was extracted from KWI-56 by the method of Smith. ${ }^{9)}$ Plasmid DNA was prepared by the rapid alkaline extraction method and was purified by Sepharose CL-4B column chromatography. ${ }^{10)}$ DNA was ligated using a DNA ligation kit (Takara Shuzo Co., Kyoto). Restriction enzymes, T4 polymerase, and a bacterial alkaline phosphatase were obtained from Toyobo Co., Osaka, and used under the recommended conditions. Artificial frameshift mutagenesis was done by an 8 mer EcoRI-linker (GGAATTCC) insertion after repair to the blunt end from cohesive end using mung bean nuclease (Toyobo Co., Osaka). The construction of deletion phages for the DNA sequencing was done using a deletion kit (Takara Shuzo Co., Kyoto). The DNA was sequenced by the dideoxy chain termination method. ${ }^{\text {i) }}$ Deaza-dGTP and Taq polymerase (Promega Co. Wisconsin) were used for the sequencing reaction.

Enzyme assay. The measurement of the lipase activity was described in a previous paper. ${ }^{5}$

Identification of amino acid composition, N-terminal amino acid sequence, and C-terminal amino acid. The purification of the lipase from KWI-56 was described in 
a previous paper. ${ }^{5}$ The purified lipase was hydrolyzed at $110^{\circ} \mathrm{C}$ for $24 \mathrm{hr}$ with $5.7 \mathrm{~N} \mathrm{HCl}$ in a sealed evacuated glass tube. Cysteine and cystine were measured as cysteic acid after performic acid oxidation. ${ }^{12}$ The hydrolysates were analyzed with a Shimadzu LC-3A amino acid analyzer by the method of Ishida et al. ${ }^{13)}$ Tryptophan was measured by the method of Bencze et al. ${ }^{14)}$ The $\mathrm{N}$-terminal amino acid sequence was identified by Edman degradation. ${ }^{15)^{\prime}}$ The C-terminal amino acid was identified using carboxypeptidase A (Seikagaku Kogyo Co., Tokyo).

Cell fractionation. The cell fractionation was done by the osmotic shock method. ${ }^{16)}$ The cells were washed with $30 \mathrm{~mm}$ Tris- $\mathrm{HCl}(\mathrm{pH} 8.0$ ) containing $0.86 \% \mathrm{NaCl}$, and were suspended in an osmotic solution $(30 \mathrm{~mm}$ Tris- $\mathrm{HCl}$ $\mathrm{pH} 8.0,20 \%$ sucrose, I mm EDTA) for $10 \mathrm{~min}$ at $25^{\circ} \mathrm{C}$ with shaking. After centrifugation at $7000 \times g$ for $10 \mathrm{~min}$, the cells were suspended in cold water and shaken for $10 \mathrm{~min}$ at $4^{\circ} \mathrm{C}$. The suspension was centrifuged at $9000 \times g$ for $10 \mathrm{~min}$. The supernatant was used as a periplasmic fraction, and the pellet was suspended in $30 \mathrm{~mm}$ Tris $-\mathrm{HCl}$ $(\mathrm{pH} 7.5)$ and sonicated. The suspension was used as a cytoplasmic fraction.

Western blotting. Proteins were electroblotted onto a nitrocellulose paper from the gel after SDS-PAGE. The paper was washed with blocking solution (100 mM Tris- $\mathrm{HCl} \mathrm{pH} 7.5,150 \mathrm{~mm} \mathrm{NaCl}, 2 \% \mathrm{BSA}$ ) and incubated with the same buffer containing rabbit antiserum against the purified lipase from KWI-56. After washing, the paper was incubated with blocking solution containing the second antibody coupled to alkaline phosphatase. The colorimetric detection was done using 5-bromo-4chloroindoxyl phosphate and nitro blue tetrazolium by the method of Blake. ${ }^{17}$

\section{Results}

Cloning of the lip from KWI-56 chromosomal $D N A$

The chromosomal DNA from Pseudomonas sp. KWI-56 (KWI-56) was partially digested with Sau3AI, and was ligated to Bam HIdigested pUC19. Then, E. coli HB101 was transformed with the recombinant plasmids. Among approximately 15,000 transformants, 18 colonies forming a clear zone on the tributyrin-LB agar were isolated. Among those, only one transformant was found to produce the lipase at $0.03 \mathrm{U} / \mathrm{ml}$. The other 17 transformants did not show any lipase activity, and seemed to contain esterase genes. The lipase-producing transformant harbored a recombinant plasmid containing $11.5-\mathrm{kb}$ of foreign DNA. It was designated pLP6.

\section{Subcloning and sequencing of the lip}

Subcloning experiments were done to locate the lip on the 11.5-kb DNA fragment. As shown in Fig. 1, E. coli $\mathrm{HB} 101$ strains harboring pLP63, pLP64 (containing a 2.9-kb $B g l$ II-EcoRI DNA fragment) and pLP65 (containing a $2.1-\mathrm{kb} \quad B g l \mathrm{II}-$ BamHI DNA fragment) formed a clear zone on the tributyrin-LB agar, although the strains harboring pLP61 and pLP62 did not. These results show that the lip exists on the $2.1-\mathrm{kb} B g l \mathrm{II}-$ BamHI DNA fragment.

The cohesive ends of the 2.9-kb BglII-EcoRI fragment from pLP64 were converted to blunt ends using the Klenow fragment. The DNA fragment was joined to the Hincll site on M13mp19. Several deletion plasmids were constructed, and the nucleotide sequences of both directions of the 2916-bp DNA fragment were identified as shown in Fig. 2. The DNA sequence indicated the presence of major four open reading frames (ORFs), positions 297 to 1470 (ORF1), 374 to 1213 (ORF2), 1476 to 2507 (ORF3), and 1565 to 2551 (ORF4), in the 2916-bp $B g l$ II-EcoRI DNA fragment.

The N-terminal amino acid sequence, AlaAsp-Gly, of the purified lipase from KWI56 found by Edman degradation is identical

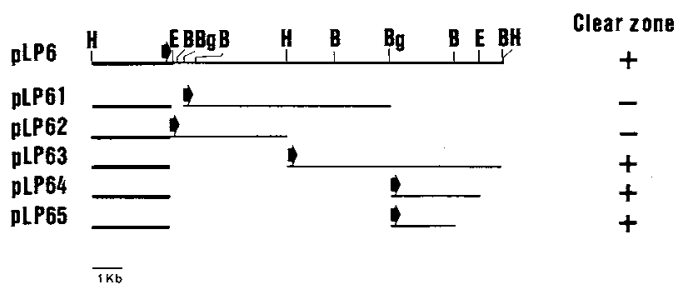

Fig. 1. Subcloning of the DNA Coding for the lip from KWI-56.

The thick and thin lines indicate pUC19 vector DNA and KWI-56 chromosomal DNA, respectively. Arrows indicate the direction of transcription from the Plac on pUC vector DNA. The lipase activity of the transformant is detected by clear zone formation on the tributyrin-LB agar containing $50 \mu \mathrm{g} / \mathrm{ml}$ of Ap. The restriction enzymes are as follows: B, Bam $\mathrm{HI} ; \mathrm{Bg}, B g l \mathrm{II} ; \mathrm{E}, E c o \mathrm{RI} ; \mathrm{H}$, HindIII. 
to the predicted amino acid sequence of the ORF1. The C-terminal amino acid was found to be Val, which coincided with that predicted from the nucleotide sequence of the ORF1. In addition, the analyzed amino acid composition agreed with that (from Ala-1 to Val320) deduced from the nucleotide sequence of this ORF (Table I). These results indicated the ORF1 contained the lip.

The ORF1 has six translational start codons, ATG, at positions $297,378,390,429,465$, and 492. The presence of a typical SD (ShineDalgarno) sequence in E. coli or in Pseudomonas, AGGAG, 12 bases upstream of the ATG codon at position 378 indicates that the lip consists of $1092 \mathrm{bp}$ starting at position 378 . Thus, the N-terminal sequence from -44 to -1 seemed to be a signal sequence, and the mature lipase was predicted to be a 320 amino acid protein with a molecular weight of $33,196$.

Table I. Amino ACid COMPOSITIONS OBSERVED FROM the Purified Lipase from KWI-56 and Calculated FROM THE NUCLEOTIDE SEQUENCE

\begin{tabular}{lrr} 
& \multicolumn{2}{c}{ No. of residues } \\
\cline { 2 - 3 } Amino Acid & Observed & Calculated \\
\cline { 2 - 3 } Asx & 32.1 & 32 \\
Thr & 30.1 & 32 \\
Ser & 21.1 & 24 \\
Glx & 21.8 & 21 \\
Pro & 11.6 & 11 \\
Gly & 35.7 & 36 \\
Ala & 39.9 & 39 \\
CysH & 0.4 & 2 \\
Val & 28.7 & 30 \\
Met & 0.9 & 1 \\
Ile & 9.9 & 11 \\
Leu & 34.0 & 33 \\
Tyr & 14.4 & 15 \\
Phe & 6.8 & 7 \\
His & 6.6 & 7 \\
Lys & 8.1 & 7 \\
Arg & 8.7 & 9 \\
Trp & 5.3 & 3 \\
\hline Total & 316.1 & 320 \\
& & \\
\hline
\end{tabular}

Calculated from the nucleotide sequence without the signal sequence. Observed by amino acid analysis and based on volume from M. W. 33,000.
Expression of the lip on E. coli

When $E$. coli JM103 (pLP64) was cultivated in $\mathrm{LB}$ containing $\mathrm{Ap}$ and $0.1 \mathrm{mM}$ IPTG (isopropyl- $\beta$-D-thiogalactopyranoside), the lipase activity reached $22.5 \mathrm{U} / \mathrm{ml}$ as shown in Table II. To investigate the cellular localization of the lipase molecule, the cells were fractionated by the osmotic shock method. Approximately $95 \%$ of the lipase activity was in the cytoplasmic fraction, and $5 \%$ in the periplasmic fraction. Very low activity was detected in the supernatant. The molecular weight of the lipases from the cytoplasmic and periplasmic fractions were measured by western blotting. The lipase protein from the cytoplasm appeared in two molecular forms (33-kD and 38-kD), although the molecular mass of periplasmic lipase was $33-\mathrm{kD}$ as a single band and consisted with that of mature lipase from KWI-56 as shown in Fig. 3.

The plasmid pLP640 (Fig. 4) had a lac promoter (Plac) in an opposite direction to pLP64. The lipase activity of JM103 (pLP640) lysate was $0.2 \mathrm{U} / \mathrm{ml}$ (Table II), and was only $1 \%$ of that of JM103 (pLP64). This fact

Table II. Lipase Activity of E. coli JM103 Carrying pLP64 Derivatives

\begin{tabular}{lcc}
\hline Plasmids & $\begin{array}{c}\text { Antibiotics } \\
\text { in LB }\end{array}$ & $\begin{array}{c}\text { Lipase Activity } \\
(\mathrm{U} / \mathrm{ml})\end{array}$ \\
\hline none & & 0 \\
pLP64 & Ap & 22.5 \\
pLP65 & Ap & 0.13 \\
pLP640 & Ap & 0.20 \\
pLP641 & Ap & 0.10 \\
pHSGL68 & Km & 0 \\
pLP65 + pHSGL68 & Ap, Km & 16.5 \\
pLP65+pHSGL68B & Ap, Km & 14.8 \\
pLP65+pHSGL68M & Ap, Km & 0.10 \\
pLP65+pHSGL68K & Ap, Km & 0.08 \\
pLP65+pHSGL68N & Ap, Km & 0.08 \\
pLP65+pHSGL68E & Ap, Km & 17.5 \\
\hline
\end{tabular}

Overnight culture of $E$. coli JM103 carrying plasmids was transferred to fresh $\mathrm{LB}$ ( $1 \%$ inoculation) containing $0.1 \mathrm{~mm}$ IPTG and $50 \mu \mathrm{g} / \mathrm{ml}$ of antibiotics (Ap and $/$ or $\mathrm{Km}$ ), and incubated at $37^{\circ} \mathrm{C}$ for $14 \mathrm{hr}$ with shaking. Cells from $5 \mathrm{ml}$ of the culture broth were washed and suspended in $5 \mathrm{ml}$ of $30 \mathrm{~mm}$ Tris- $\mathrm{HCl}(\mathrm{pH} 7.5)$. The suspension was treated by ultrasonic disintegration, and its lipase activity was measured. 
suggested that the lip on pLP64 was mostly expressed by the Plac in the pUC vector DNA.

On the other hand, the lipase activity of JM103 (pLP65) reached only $0.13 \mathrm{U} / \mathrm{ml}$ in spite of the presence of the lip. JM103 carrying $\mathrm{pLP} 641$, which had an artificial frame shift mutation by the insertion of an 8 mer
EcoRI-linker DNA (GGAATTCC) in the BamHI restriction site (position 2099), also produced $0.10 \mathrm{U} / \mathrm{ml}$ of the lipase (Fig. 4 and Table II). In these cases, only very low activity was detected in the supernatant. These results suggested that the downstream region was important for high expression of the lipase

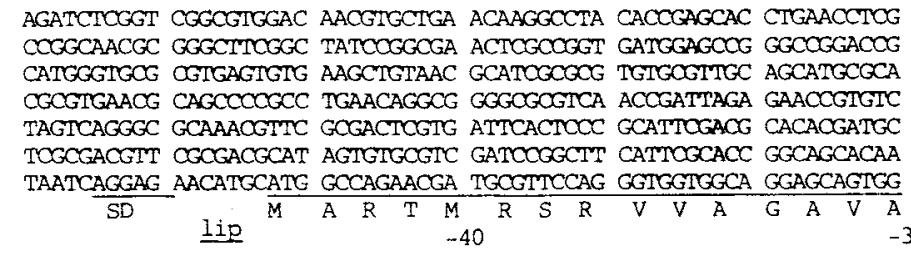

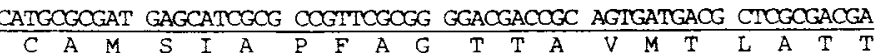
$-20$

481 CGCAOGOGGC GATGGOGGCG ACOGOGCCOG CCGATGGCTA CGOGGCGAOG OGTTATCCGA $- 1 \longdiv { 1 }$ 10 41 TCATCCTCGT GCACGGGCTC TOGGGTACOG ACAAGTACGC CGGOGTGGTC GAGTATTGGT $\begin{array}{lllllllllllllllllll}I & L & V & H & G & L & S & G & T & D & K & Y & A & G & V & V & E & Y & W \\ & & & & & & & & & & & & \end{array}$

601 ATGGCATCCA GGAAGACCTG CAGCAGAACG GIGCGACCGT CTACGTOGCG AACCTGTCGG 40 50

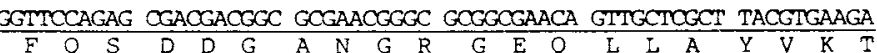
60 70 CGGTGCTCGC GGCGACGGGC GCGACCAAGG TCAATCTOGT OGGCCACAGC CAGGGOGGCC $\begin{array}{llllllllllllllllllll}V & L & L & A & A & T & G & A & T & K & V & N & L & V & G & \text { H } & \text { S } & \text { Q } & G & G \\ 90\end{array}$ ACGTCGOG CTATGICGCG GCOGTCGCCC COCATCTOGT GGOGTOGGIG AOGACGATCG $\begin{array}{llllllllll}100 & D & L & V & A & S & V & T & T & 1 \\ & & & & & & & & & \\ 110\end{array}$ \begin{tabular}{c} 
GCACGCOGCA TCGCGGCTCC GAGTTTGCCG ACTTCGTCCA GAACGTGCTG GCGTACGATC \\
\hline T
\end{tabular} 120 30

CGACCGGGCT TTCGTCATCG GTGATCGCCG CGTTCGTCAA TGTGTTCGGC ATCCIGACGA

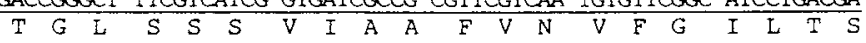
GCAGCAGCCA CAACAOGAAC CAGGACGCGC TOGOCGCGCT GCAGACGCTG ACCACOGCCC 160

1021 GGGCTGCCAC GTACAACCAG AACTATCCGA GCGCGGGCCT GGGIGCGCCG GGCAGTTGCC $\begin{array}{llllllllllllllllllll}A & A & T & Y & N & Q & N & Y & P & S & A & G & L & G & A & P & G & S & C & Q\end{array}$ 1081 AGACOGGOGC GCOGACOGAA ACOGTCGGCG GCAACACGCA CCTGCTGTAT TOGTGGGCCG 200 210

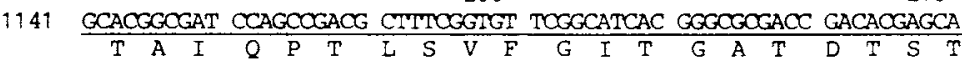

1201 220 230

1261 COGGCAOGG GATGATCAAC CGOGGCICOG GGCAGAAOGA OGOGCTOGTG TCGAAGTGCA

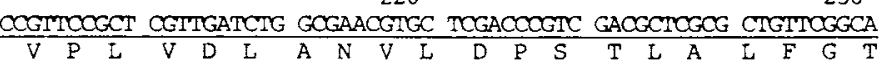
240 $\begin{array}{lllllllllllllllllllll}G & T & V & M & I & N & R & G & S & G & Q & N & D & G & L & V & S & K & \text { C } & S \\ & & & & 260\end{array}$

1321 GTGOGCIGTA OGGCAAGGTG CIGAGTACGA GCTACAAGTG GAACCACCTC GACGAGATCA $\begin{array}{lllllllllllllllllllll}A & L & Y & G & K & V & L & S & T & S & Y & K & W & N & H & I & D & E & \text { I N } \\ & & & & & & & & \end{array}$

1381 ACCAGCIGCT OGGOGTGOGC GGOGOGTATG OGGAAGATCC GGTOGCGGTG ATCOGCACGC 300

Fig. 2. 
1441

1501

1741

1801

2041

2221

2461

330

2521

2581

2641

2701

2761

2821

2881 30 50 70 A $\mathrm{V}$

ATGOGAACOG GCTGAAGCTG GCGGGCGTGT AATOCETTAC GTCACGTGAA GGACGCGCGC

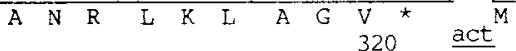

$$
320
$$

OGCTGGOGCG GCGCGCOGIG GTCTATGGIG TCGTAGGGCT GGOGGCGATT GOCGGCGIGG

$$
\begin{array}{lllllllllll}
L & A & R & R & A & V & V & Y & G & V & V \\
10 & & & & & & & & & \\
\hline
\end{array}
$$

CGATIIGGAG CGGCGOGGGC TGGCATCGCG CAAOGGGOGC TTCOGGOGAG TOGCOG $\begin{array}{llllllllllllllllllll}M & W & S & G & A & G & W & H & R & A & T & G & A & S & G & E & S & P & E & A\end{array}$

40

MICGGIGK AGGGGGATOG GITACCGCAC CGCCGO $\begin{array}{lllllllllllllllllllllllllll}S & V & A & G & G & S & V & T & A & P & P & Q & A & A & V & P & A & S & T & G\end{array}$

60

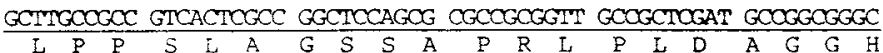

80

ATCIOGCGAA GTCGCGCGCA GTGDGGGATT TCTTCGACTA CTGCCTCACC GCGCAGAGCG

$$
\begin{array}{llllllllllll}
L & A & K & S & R & A & V & R & D & F & F & \\
90 & & & & & & & & & &
\end{array}
$$

ACCTGAGCGC GGCOGGICTC GACGCGTTCG TCATGOGCGA GATTGOOGCA CAGCTCGACG $\begin{array}{llllllllllllllllllll}L & S & A & A & G & L & D & A & F & V & M & R & E & I & A & A & Q & L & D & G\end{array}$ $110 \quad 120$

GPACOGTTGC GCAAGCCGAG GCGCTCGACG TGIGGCACOG GTATCGOGOG TATCTCGACG $\begin{array}{llllllllllllllllllll}T & V & A & Q & A & E & A & L & D & V & W & H & R & Y & R & A & Y & L & D & A\end{array}$ $130 \quad 140$

CACTOGCGAA ATTGCGCGAT GCCGGCGOGG CCGACAAGIC CGACCIGGGC GOGTTGCAAC $\begin{array}{llllllllllllllllllll}I & A & K & I & R & D & A & G & A & A & D & K & S & D & L & G & A & L & Q & L\end{array}$ 150

TCGCGCTOGA CCAGCGCGCG TCGATCGCGI ACCGCACGCT OGGCGACTGG AGCCAGCOGT

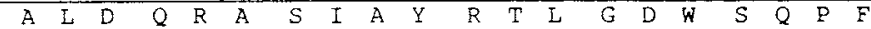
$170 \quad 180$

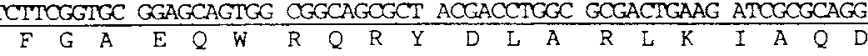
$190 \quad 200$

ATCCCAOGCT GACGGATGCG CAGAAGGCOG AACGGCTCGC GGCGCTCGAA CAGCAGATGC

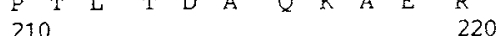

CGBCOGAOGA ACGCGCOGOG CAGCAGCACA TOGACCAGCA GCGIGCGGOG ATCGACCAGA $\begin{array}{llllllllllllllllllll}A & D & E & R & A & A & Q & Q & H & I & D & Q & Q & R & A & A & I & D & Q & I\end{array}$ $230 \quad 240$

TOGCGCAATT GCAGAAGAGC GGGGCGACAC COGATGCGAT GCGCGCACAA CIGACGCAGA $\begin{array}{llllllllllllllllllll}A & Q & L & Q & K & S & G & A & T & P & D & A & M & R & A & Q & L & T & Q & T\end{array}$ $250 \quad 260$

OGCIOGCOC OGAAGOGGCC GCGCGOGIOG OGCAGATGCA GCAGGAOGAC GCATCGIGGC $\begin{array}{lllllllllllllllllllll}I & G & P & E & A & A & A & R & V & A & Q & M & Q & Q & D & D & A & S & W & Q\end{array}$ $270 \quad 280$

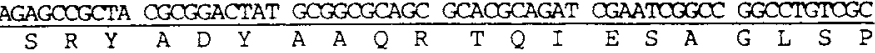
$290 \quad 300$

gGCAGGATOG CGAOGOGCAG ATCGCOGCGC TGOGGCAGOG OGTGTTCACG CGGCCOGGOG $\begin{array}{llllllllllllllllllll}Q & D & R & D & A & Q & I & A & A & L & R & Q & R & V & F & T & R & P & G & E\end{array}$ 310

AAGCOGTGCG TGOGGCATCG CTOGATOGOG GGGCGOGCAG OGCGOOGTAA CGCGGOCGGC

GCAGCGCATG ACOGTOGCTA TGCOGOGOGC GTGAGATCCC GOGGCAGGTG TTGCTOGATG GTATIGCOCA GCGTGICGAA CGOOGGCTCG ATGCCITOGT GOOCGAOOCA TOCATAACOG AGCAGCAGGC COOGCOGOSC GGTGTCGAGG CTGCTGTAGT AGCTGGIGAG OGGGCGCAOG ATCAOGOCOG CATOGAAOGC GCTCTGCGIG ACOGCGOGAT OGTOGCAGGC GIOGGGCAGG COGAGCAOGA GATGCAGGCC TGCCTCGTCC CCCATCACOG GCAGOGOGTC GCOGAAGOGC GOCOGGATOG OGIOGATCAT CAGITGOOGG OGCTCGCOGT ACAGOGIGOG CATOCGICTG AOGTGOGAAG TCAGGIGGCC GTCCATGAAT GAATTC

Fig. 2. Nucleotide Sequence of the $2.9 \mathrm{~kb} \mathrm{BglII}-E c o$ RI Fragment Containing the lip and the act.

The entire amino acid sequence deduced from the nucleotide sequence is shown below the coding region. The arrow indicates the cleavage site of the lipase with signal peptidase, which was estimated from the $N$-terminal amino acid sequence (underlined) from the purified lipase. SD indicates the SD sequence of the lip. The double underline indicates the common sequence of lipase, G-X-S-X-G. Open and shaded boxes indicate the possible translational start codons and the SD-like sequences of the act, respectively. 


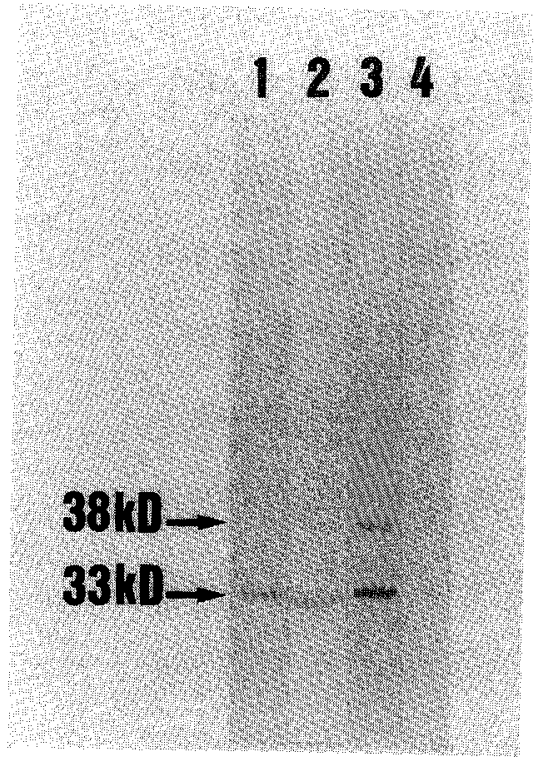

Fig. 3. Western Blot Analysis of the Lipase in Cell Fractions of E. coli HB101 (pLP64).

Lane 1, purified lipase from KWI-56; lane 2, periplasmic fraction of HB101 (pLP64); lane 3, cytoplasmic fraction of HB101 (pLP64); lane 4, cell lysate of HB101 (pUC19).

activity.

To find whether the downstream region has a trans-acting function, complementation tests were carried out. A plasmid, pHSGL68, was constructed by ligating the $1.9-\mathrm{kb}$ Pst I-EcoRI fragment from pLP64 to EcoRI and PstI digested pHSG299 which is a $\mathrm{Km}$ resistant pUC type vector (Fig. 4). When JM103 carrying both pLP65 and pHSGL68 was cultivated in LB containing $0.1 \mathrm{~mm}$ IPTG, Ap, and $\mathrm{Km}$, the lipase activity of the lysate reached $16.5 \mathrm{U} / \mathrm{ml}$ (Table II). JM103 (pHSGL68) did not produce the lipase. These results suggested that an activator gene (act) was located downstream of the lip, and the gene product enhanced the lipase activity about 200 -fold as a transelement.

\section{Nucleotide sequence of the act}

To determine the localization of the act, derivatives from pHSGL68 were constructed using the restriction cleavage sites, BstEII, $M l u \mathrm{I}, K p n \mathrm{I}, N o t \mathrm{I}$, and EcoT22I at position $1640,1822,1860,2295$, and 2630 (Fig. 4). To

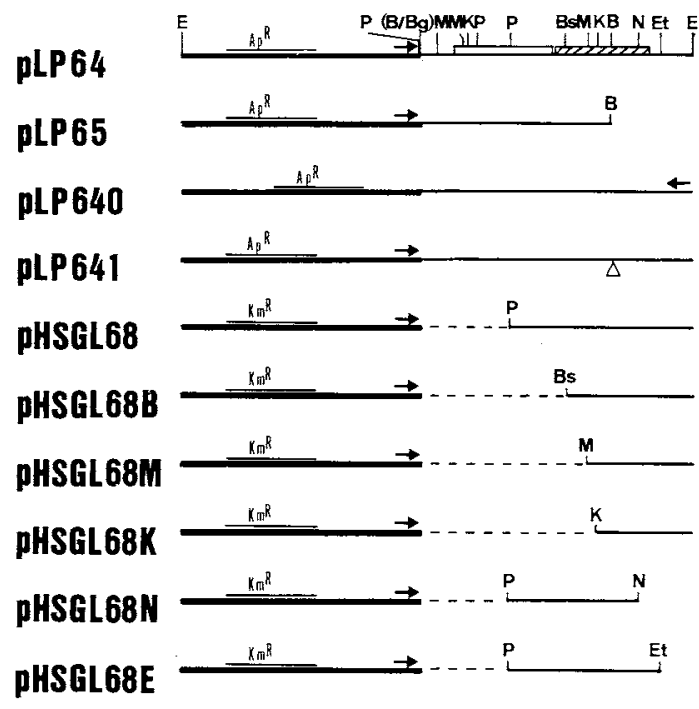

\section{$1 \mathrm{~kb}$}

Fig. 4. Restriction Maps of pLP64 and Its Derivatives. The thick and thin lines indicate vector DNA and KWI-56 chromosomal DNA, respectively. An open and a shaded box indicate the ORFs of the lip and the act, respectively. Arrows indicate the direction of transcription from the Plac on PUC vector. A triangle under the line indicates the linker insertion site for the artificial frameshift mutation. Restriction enzymes are as follows: B, BamHI; Bg, BglII; Bs, BstEII; E, EcoRI; Et, EcoT22I; K, KpnI; M, MluI; N, NotI; P, PstI.

construct plasmids pHSGL68B, pHSGL68M, pHSGL68K, pHSGL68N, and pHSGL68E, pHSGL68 was digested by PstI-BstEII, Pst $\mathrm{I}-M l u \mathrm{I}, P_{s t} \mathrm{I}-K p n \mathrm{I}, N o t \mathrm{I}-E c o \mathrm{RI}$, and EcoT22I-EcoRI, respectively. The resulting fragments were treated with $\mathrm{T} 4$ polymerase and self-ligated. The lipase activity of $E$. coli JM 103 carrying both pLP65 and the derivative was measured. pHSGL68B and pHSGL68E increased the lipase activity $(14.8-17.5 \mathrm{U} / \mathrm{ml})$ in JM103, but pHSGL68M, pHSGL68K, and pHSGL68N did not $(0.08-0.1 \mathrm{U} / \mathrm{ml})$ as shown in Table II. These results showed the start and stop codons of the act must be located upstream of the MluI site and downstream of the NotI site, indicating that either the ORF3 or the ORF4 contained act. In pHSGL68B, it was expected that the translation was started from its own start codon and/or the lac $Z$ start codon on the vector. The ORF3 had two 
translational start codons, GTG, at position 1665 and 1761 between the BstEII site and the MluI site, but the ORF4 did not. The ORF3 was in the same translational reading frame as the vector's lac $Z$ gene, and resulted in the expression of an $\beta$-galactosidase fusion protein. Thus, these results indicated that the act was presented in the ORF3 which encoded a polypeptide of 344 amino acid residues with a molecular weight of 36,544 . No homologies between this protein and other proteins in the NBRF-PIR and the SWISS-PROT data bases could be found using the method of Lipman and Pearson. ${ }^{18)}$ This ORF existed at $7 \mathrm{bp}$ downstream of the lip with the same orientation, and had eight possible translational start codons at positions 1476, 1518, 1533, $1557,1563,1626,1665$, and 1761. The SDlike sequences, GAGGCG and AGGCAG, were in front of GTG codons at positions 1626 and 1665 , respectively.

\section{Discussion}

Kugimiya et al. ${ }^{3)}$ and Aoyama et $a .^{4)}$ reported the cloning of lipase genes from $P$. fragi IFO-3458 and IFO-12049. The nucleotide sequences of these genes were identical with each other except for 3 nucleotides. On a taxonomical study, KWI-56 was a close relative of $P$. cepacia ${ }^{5}$ and was different from $P$. fragi according to rRNA homologies. ${ }^{19,20)}$ In spite of the difference in the taxonomic classification, there is $30 \%$ overall homology between the two lipases from KWI-56 and IFO-12049. This result suggests that the structure of lipases from genus Pseudomonas might be similar.

When comparing the lipases from Pseudomonas to that of Staphylococcus, ${ }^{21,22)}$ five regions of amino acid sequence were conserved, atthough the overall homology was very low. In addition, the orders of the five conserved regions on the primary structures of these lipases were also identical (Fig. 5). Therefore the conserved regions may be essential for the expression of the enzyme activity. In fact, the 2nd conserved region includes the common sequence of lipases, Gly-X-Ser-X-Gly, and the serine in this peptide is considered as an active serine residue (Ser-87). Furthermore, one of the histidine and aspartic acid residues in the conserved regions might form a catalytic center with the Ser-87, Ser-His-Asp triad, as was already shown in the lipases from Rhizomucor miehei and human pancreas by $\mathrm{X}$-ray crystallography. ${ }^{23,24)}$

No homology except for the common sequence of Gly-X-Ser-X-Gly was found between KWI-56 and other lipases from most of the eukaryotic sources such as pancreas, ${ }^{25,26)}$ liver $^{27,28)}$ and eukaryotic microorganisms. ${ }^{29.30)}$ However, the sequence of His-X-Asp-X-Ile in the 5 th region as shown in Fig. 5 existed in the human gastric ${ }^{31)}$ and the rat lingual ${ }^{32)}$ lipases as well.

In E. coli, $95 \%$ of lipase activity was located in the cytoplasm, and the lipase appeared in two molecular forms (33-kD and 38-kD). On the other hand, it was confirmed that the lipase also existed in the periplasm, and its molecular mass was $33-\mathrm{kD}$ as a single molecule (Fig. 3). These results suggest that the cloned lipase is produced as a $38-\mathrm{kD}$ proenzyme, and cleaved by signal peptidase to be secreted into the periplasmic space as a $33-\mathrm{kD}$ mature enzyme. The 33-kD lipase may be a membrane-bound structure in $E$. coli because of its hydrophobicity, and the minor part is detected in the periplasm.

The act was found downstream of the lip, and the lip and act might be expressed as a polycistronic mRNA in E. coli (pLP64) using Plac, because consensus sequence for the $E$. coli promotor was not found on upstream of the act. Though the act has eight possible translational start codons, it is not clear which codon is used in E. coli. Further work is needed to clarify this question by identifying the $\mathrm{N}$-terminal sequence and molecular weight of the purified activator.

The activation mechanism by the activator is not understood. It is supposed that the hypothetical mechanisms include the following: (1) activation at the level of transcription; (2) stabilization of the lipase mRNA; (3) activation at the level of translation; (4) 

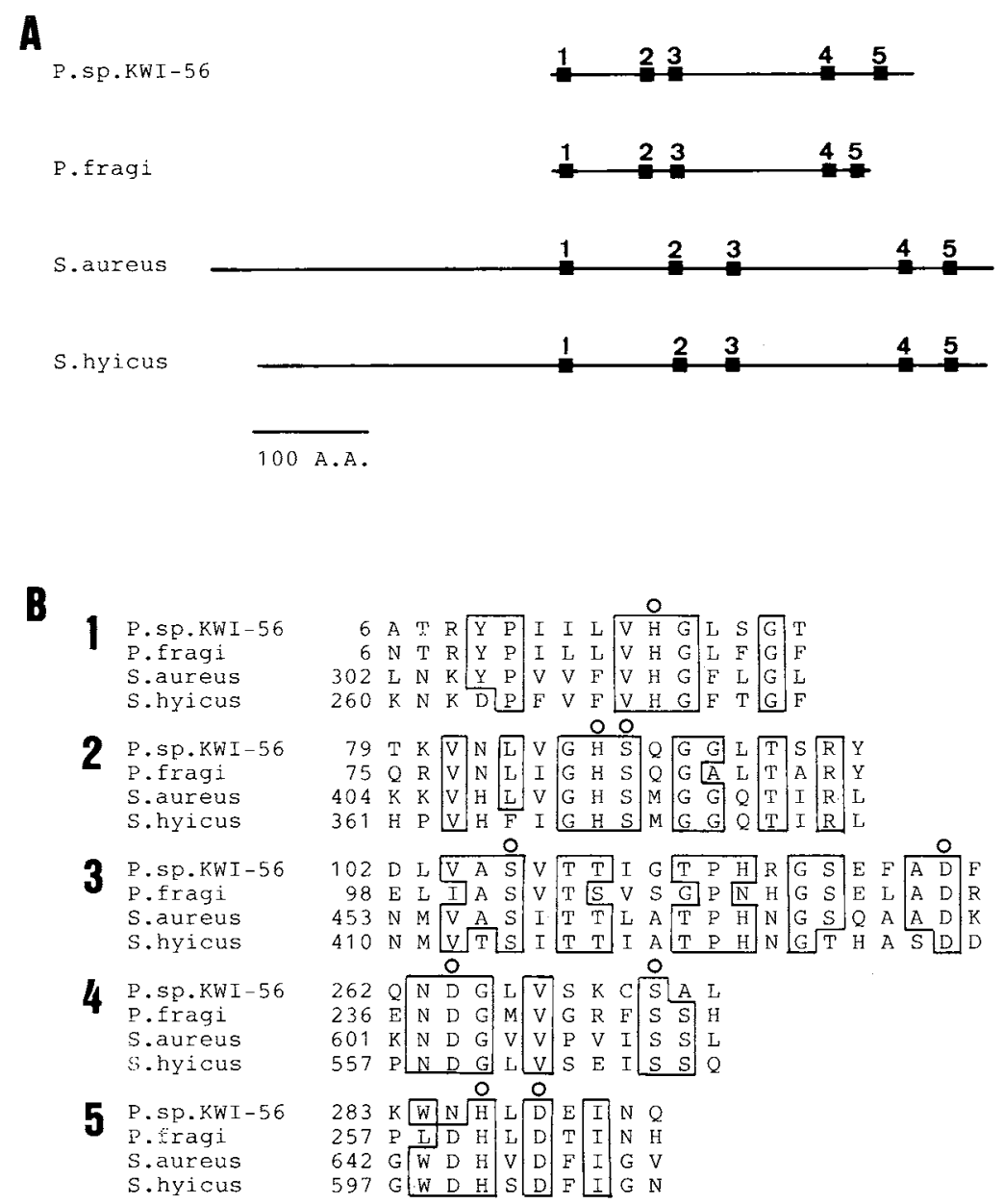

Fig. 5. Partial Homology of the Amino Acid Sequences among the Lipases from KWI-56, P. fragi IFO-12049, ${ }^{47}$ S. hyicus ${ }^{21)}$ and S. aureus. ${ }^{22)}$

A: Position of the conserved regions (thick lines, 1-5) on the lipase primary structures as a mature protein (KWI-56) and pre-proteins (others)

B: Homologous amino acid residues in the conserved regions (1-5) are boxed. The aspartic acid, histidine, and serine residues that are identical in all sequences are marked by circles. The numbers beside the sequences indicate the amino acid numbers of mature protein (KWI-56) and each pre-protein (others) from their $\mathrm{N}$-terminus.

processing or folding of the lipase precursor; and (5) activation by co-factor. Generally, the regulatory mechanism of expression of a gene functions at the level of transcription. In this case, the role of the transcriptional activator is a positive factor which increases the amount of mRNA by binding to operator or repressor. However, this activation system must not function in the case of the lip, because the lip was controlled by the Plac on $\mathrm{pUC}$ vector and the promoter from KWI-56 does not play an important role in the lipase expression in $E$. coli.

On the other hand, the activation of lipase by a co-factor is known for the lipases from Saccharomycopsis lypolytica, ${ }^{33)}$ human pancreas, ${ }^{34)}$ and castor beans. ${ }^{35)}$ If a co-factor is essential for the expression of the lipase activity from KWI-56, a drastic decrease of the activity may be found in some purification step, but 
it was not found in our previous purification experiment. The purified enzyme, which showed a single band on SDS-PAGE, had lipase activity, and its molecular weight, 33,000, consists of that from the nucleotide sequence, so there is no possibility that a co-factor combines with the lipase for the expression of the lipase activity. ${ }^{5)}$ Accordingly, it seems that the act encodes neither a co-factor nor a co-factor synthesizing enzyme.

Further investigations are in progress to clarify the activation mechanism mentioned above.

\section{References}

1) M. Okada, K. Takeuchi and A. Toh-e, J. Ferment. Technol., 64, 363 (1986).

2) S. Wohlfarth and U. K. Winkler, J. Gen. Microbiol., 134, 433 (1988).

3) W. Kugumiya, Y. Otani, Y. Hashimoto and Y. Takagi, Biochem. Biophys. Res. Commun., 141, 185 (1986).

4) S. Aoyama, N. Yoshida and S. Inouye, FEBS Lett, 242, 36 (1988).

5) T. Iizumi, K. Nakamura and T. Fukase, Abstracts of Papers, the Annual Meeting of the Japan Society for Bioscience, Biotechnology, and Agrochemistry, Fukuoka, April, 1990, p. 434.

6) T. Iizumi, K. Nakamura and T. Fukase, Agric. Biol. Chem., 54, 1253 (1990).

7) C. Yanisch-Perron, J. Vieira and J. Messing, Gene, 33, 103 (1985).

8) S. Takeshita, M. Sato, M. Toba, W. Masahashi and T. Hashimoto-Gotoh, Gene, 61, 63 (1987).

9) M. G. Smith, "Methods in Enzymology," Vol. 12, Part A, Academic Press, New York, 1967.

10) T. Maniatus, E. F. Fritsch and J. Sambrook, "Molecular Cloning: A Laboratory Manual," Cold Spring Harbor, N.Y., 1982.

11) F. Sanger, S. Nicklen and A. R. Coulson, Proc. Natl. Acad. Sci. U.S.A., 74, 5463 (1977).

12) S. Moore, J. Biol. Chem., 238, 235 (1963).

13) Y. Ishida, T. Fujita and K. Asai, J. Chromatogr., 204, 143 (1981).

14) W. L. Bencze and K. Schmid, Anal. Chem., 29, 1193 (1957).

15) S. Tsunasawa, J. Kondo and F. Sakiyama, $J$. Biochem., 97, 701 (1985).
16) H. C. New and L. A. Heppel, J. Biol. Chem., 240, 3685 (1965).

17) M. S. Blake, K. H. Jhonston, G. J. Russell-Jones and E. C. Gotschlich, Annal. Biochem., 136, 175 (1984).

18) D. J. Lipman and W. R. Pearson, Science, 227, 1435 (1985).

19) N. J. Palleroni, R. Kunisawa, R. Contopoulon and M. Doudoroff, Int. J. Syst. Bacteriol., 23, 333 (1973).

20) G. S. Byng, J. L. Jhonson, R. J. Whitaker, R. L. Ghewrna and R. A. Jensen, J. Mol. Evol., 19, 272 (1983).

21) F. Gozt, F. Popp, E. Korn and H. Schleifer, Nucl. Acids Res., 13, 5895 (1985).

22) C. Y. Lee and J. J. Iandolo, J. Bacteriol., 166, 385 (1986).

23) L. Brady, A. M. Brzozowski, Z. S. Derewenda, E. Dodson, G. Dodson, S. Tolley, J. P. Turkenburg, L. Christiansen, B. Huge-Jensen, L. Norskov, L. Thim and U. Menge, Nature, 343, 767 (1990).

24) F. K. Winkler, A. D'Arcy and W. Hunziker, Nature, 343, 771 (1990).

25) J. Decaro, M. Boudouard, J. Bonical, A. Guidoni, P. Desnuella and M. Robery, Biochim. Biophys. Acta, 671, 129 (1989).

26) F. S. Mickel, F. Weidenbach, B. Swarovsky, K. S. LaForge and G. A. Scheele, J. Biol. Chem., 264, 12895 (1989).

27) S. Datta, C. Luo, W. Li, P. Van Tuinen, D. H. Ledbetter, M. A. Brown, S. Chan, S. Liu and L. Chan, J. Biol. Chem., 263, 1107 (1988).

28) M. C. Komarony and M. C. Schotz, Proc. Natl. Acad. Sci. U.S.A., 84, 1526 (1987).

29) Y. Kawaguchi, H. Honda, J. Taniguchi-Morimura and S. Iwasaki, Nature, 341, 164 (1989).

30) Y. Shimada, A. Sugihara, T. Tizumi and Y. Tominaga, J. Biochem., 107, 703 (1990)

31) M. W. Bodmer, S. Angal, A. T. Yarranton, T. J. R. Harris, A. Lyons, D. J. King, G. Pieroni, C. Riviere, R. Verger and P. A. Lowe, Biochim. Biophys. Acta, 909, $237(1087)$.

32) A. J. P. Docherty, M. W. Bodmer, S. Angal, R. Verger, C. Riviere, P. A. Lowe, A. Lyones, J. S. Emtage and T. J. R. Harris, Nucl. Acid Res., 13, 1891 (1985).

33) K. Gomi, Y. Ota and Y. Minoda, Agric. Biol. Chem., 50, 2525 (1986)

34) M. Semeriva and P. Desnuelle, Adv. Enzymol., 48, 319 (1979).

35) R. L. Ory and B. Borgstrom, Biochim. Biophys. Acta, 212, 521 (1970). 